ned as a mere luxury for countries that still have a limited research base, active participation in major international science projects provides enormous stimulation, immediate access to tutorial support and a huge amount of data and information, and often the possibility to carry out significant tasks in the home country. Supporting membership of central and east European countries and their agencies in the larger internationally-based research organizations thus represents an attractive option for governments: encouraging such a strategy may effectively offer a way to envisage increased research funding in these countries.

\section{Pragmatic Mechanisms}

Given that renewal and development in east and central Europe will take at least a generation whereas only existing mechanisms and short term measures for support are available, Professor Jolles summarized the participants' main recommendations for future initiatives. They are:

- place refereeing on an international basis and call for international evaluation panels when internal groups are too small, homogeneous or manipulated;

- exploit membership and participation in international networks (ESF, Université de l'Europe, NATO, EEC, EPS, CERN, etc.);

- use western facilities with financial help for mobility;

- build up bilateral arrangements.

So there is no miracle medicine but a mixture of mechanisms: use whatever help exists as together you might be pushed over the mountain.

All who participated were very grateful for the generous financial support provided by the NATO Scientific Affairs Division that allowed useful options and working strategies to be discussed: they hoped a similar workshop along the same lines would be held in two to three years to evaluate progress - only this time outside western Europe.

\section{Jacob \\ EPS President
E.W.A. Lingeman Chairman Physics and Society}

\section{1st EPS Southern European School of Physics}

\section{Dynamical Processes in Molecular Physics}

\author{
Avila, Spain, 1-13 September 1991
}

As it is not usual for laboratories in southern Europe to pay for Ph.D. students to attend summer schools, the EPS Action Committee for Physics and Development launched a series of schools with a "southern emphasis", where funding would be provided to invited students. Thanks to the generosity of some key sponsors, notably the EC, NATO and some Spanish sources, the first EPS Southern School of Physics, held in the charming walled town of Avila, Spain, from 1-13 September, was a great success. There were 56 participants with lectures given by nearly 20 prominent experts: the Director of the School was Professor Gerado DelgadoBarrio from Madrid. The exciting topics covered included some particlarly interesting ones such as the physics of small molecular aggregates. An interesting novelty was introduced into the tutorials: participants were able to work with specially developed software on computers loaned in part by IBM Spain, and then take the programs away for later use.

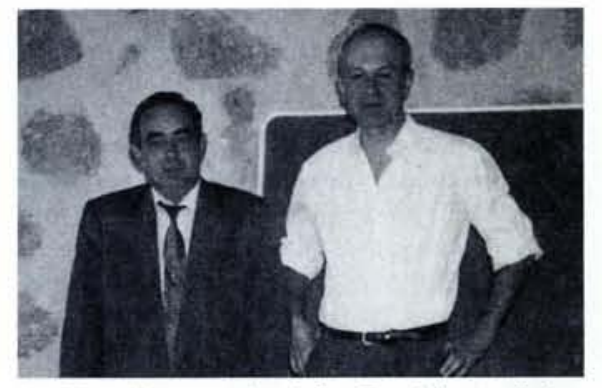

A. Tiemblo, on the left, President of the Royal Spanish Physical Society, and G. Delgado-Barrio, Director of the 1st EPS Southern European School of Physics.

The School is managed by an Advisory Board representing the Divisions, national societies and the main funding agencies. The Board is presently considering a proposal by Professor C. Fotakis on behalf of the Institute of Electronic Structure and Lasers of the Foundation for Research and Technology, Hellas, to hold the next school in Crete on Lasers and Applications.

\title{
History of Physics Group Consolidates
}

It is slightly over two years since EPS Council approved the formation of the Interdivisional Group for the History of Physics, which came together following the organization of conferences in Pavia (1983), Munich (1986) and Paris (1988) on the use of the history of science in physics teaching. Recent activities along the same lines include the organization of a conference "History Teaching Physics" (Cambridge, UK, August 1990) and of history of physics sessions at the EPS-8 General Conference in September 1990.

The Group continues to see as one of its aims the organization of meetings on the history of physics and on its application in science education. The Group's Chairman, Fabio Bevilacqua, Professor of Physics in Pavia University's Physics Department, is therefore very pleased to be able to announce that a project to hold the first-ever European History of Physics Conference has come to fruition: it will take place at the Villa Olmo in Como, Italy, in May 1992 and details will be available shortly.

Meanwhile, Dr. Antonio Moreno-Gonzalez of the Escuola Universitaria de Formación del Professorado, Universidad Complutense, Madrid, has sent out the first circular for a Europhysics Study Conference he is organizing titled "History of the Physical-Mathematical Sciences and the Teaching of Sciences" to be held at the University on 9-11 September 1992. This meeting will offer an opportunity for physics teachers from throughout Europe to discuss recent experience on the didactic applications of science history.

Other activities in the area of science teaching include a project to develop guidebooks for teachers, while the third of the Group's goals is to promote the preservation and cataloging of archives and collections of scientific instruments. 